\title{
Enrolling Local Strategic Actors in Public Portal Development
}

\author{
Agneta Ranerup and Annelie Ekelin \\ Department of Applied IT, University of Gothenburg, 41296 Göteborg, Sweden \\ ranerup@ituniv.se
}

School of Computing, Blekinge Institute of Technology, 37179 Karlskrona, Sweden

annelie.ekelin@bth.se

\begin{abstract}
This paper focuses on the seemingly routine but essential aspects of network formation by actors in an E-government context. A qualitative case study is used to explore portal development in public healthcare. The theoretical framework applied is Actor-Network Theory (ANT). The research question is: What factors contribute to the enrolment of strategic local actors in technology development in E-government? The results of the study show that the basic functionalities are of strategic importance for the enrolment of local actors in the portal development and its use. These functionalities act as enrolment devices. In complex environments, critical success factors for network formation require local support based on present usefulness of the functionalities and on long-term project organization that safeguards their future development.
\end{abstract}

Keywords: Portal, development, healthcare, Actor Network Theory, enrolment.

\section{Introduction}

The development of E-government systems is a complex and challenging endeavour since it involves many actors and many logics. From both a practical as well as a research perspective, successful network formation in E-government development by actors is therefore of particular interest [2, 12, 14, 23, 30]. This paper uses a qualitative case study of national healthcare portal [11] development to investigate the reasons for the success or failure of network formation in the complex political context of E-government. The paper's focus is the development of a national Swedish public healthcare portal in which various local county councils are involved in the development of the portal. Thus, this is a process case study of technology development in an E-government context [33].

The context of the case study is a Western country where there is significant public funding of healthcare and where there is very high Internet usage by the general public. Although the main actors are the semi-autonomous government entities (the county councils), national government authorities and other organizations are also involved. The success or failure of the portal is judged based on its use by healthcare users and by the support it receives from the county councils. 
A theoretical framework is required in order to examine the development of a national healthcare portal in the context of E-government where there are many actors and many logics. Stakeholder analysis [29] is one possible framework for such a study since it considers the diversity of actors and their interests. However, the focus of our study is not the appearance of different interests per se. Instead, our focus is the specific actions and opinions of actors in the portal development that precedes enrolment [4] by a certain group of strategic local actors (the county councils). Therefore, an alternative framework for this study, and the one we have chosen, is Actor-Network Theory (ANT). According to an influential article [14], ANT is an excellent framework for understanding the politics of E-government project trajectories. Our paper thus contributes to E-government research with specific reference to those studies that use ANT [14, 26, 30, 33, and others]. The research question is: What factors contribute to the enrolment of strategic local actors in technology development in E-government?

\section{Previous Studies}

There are a few E-government studies that use ANT as well as some related studies of technology development in healthcare that use ANT. One study uses the concept of symmetry in ANT to examine the use of technology in the context of national border controls [31]. This study concludes that since people (the social aspects) and goods (the technological aspects) have several very similar problems in this context, symmetrical analysis is appropriate. Another study suggests that an ANT analysis of processes in the public sector is an excellent way to understand project trajectories and network formation and to distinguish between global actors and local actors [14]. These authors recognize the emergent power of actors as a central tenet in such processes, determining their success or failure. In a similar vein, in its focus on global and local actors, another study finds the latters' interests are much weaker than the formers' interests [23]. The subject of another study is the organizational outcome of an online analytic processing tool in a municipal environment [16]. This study focuses on the successive enrolment of diverse groups of actors within the organization as well as on the modifications of their perceptions of the system. Another study presents an ANT analysis of actors and objectives when citizens use a Decision Support System in pension reform as a part of an attempt to influence their behaviour [26]. To a limited extent, two studies propose the use of ANT in an E-government case context [1, 12]. Lastly, one study looks at contextual dynamics in health information systems in public healthcare with a focus on the dynamics of the elements of content and context [6]. This study tests a particular methodological approach by focusing, structuring and presenting the case study based on process events.

With one exception [31], these studies focus on broad development processes and the network formation of actors in E-government. However, none of these studies examines the particularities of the enrolment of one (strategic) group of actors other than the key dominating actors in the initial stage of a translation process [13]. Our aim is to use ANT as an approach to investigate factors that contribute to the enrolment of strategic local actors in a process of technology development in Egovernment. Thus, similar to the approach taken by the authors who explore an eventbased network [6], our study tests a specific research approach in its exploration of the role of local strategic actors in network development. 


\section{Theoretical Framework}

The theoretical framework for this study builds on ANT, the sociology of translation and the concepts of problematisation, interessement and enrolment [4]. While ANT is a continuously developing theory that emerged in seminal texts [4], there have also been relatively recent contributors [5] and [8]. This paper uses this framework by applying certain concepts to a process in a specific field of praxis (the process by which an E-government system develops). Next we present a brief account of these concepts.

The classic ANT study, involving scallops, fishermen and researchers in St. Brieuc Bay, France, presents a simple but telling account that introduces important concepts [4]. The study describes how certain actors (the researchers) attempted to enrol or align other actors (scallops and fishermen) in a process with the objective of ensuring the survival of the scallop industry. To that end, the researchers recommended the use a towline to grow the scallops. The towline is the enrolment device in this process in which problematisation is the first phase. The researchers identify themselves as indispensable resources for the solution to the problem they defined; the scallops' and the fishermen's roles are defined more generally. Thus, the initiators (the key actors) identify themselves, in terms of ANT, as an obligatory passage point. All actors have to pass that point in order to reach a solution.

In the second phase, interessement, initiators try to convince other actors that the previously defined ideas match their own interests. The concept of interessement etymologically is related to the notion of being in between (inter-esse), that is, of being interposed. According to [4], actors may be defined in other, more competitive ways. However, by building devices for use by the actors and their allies, initiators shape their identities. This phase consists of trials of strength whose outcome determines the solidity of the previously defined solution. Incentives are also created for actors to enlist their support. 'Interessement is the group of actions by which an entity attempts to impose and stabilize the identity of other actors [...]. Different devices are used to implement these actions' [4, pp. 207-208]. Put simply, the enrolment devices may be different artefacts, such as the towlines in the scallops study. They may also be IT systems.

The third phase is enrolment. In this phase, alliances of actors form around the proposed solution. In some studies [19,4] actors achieve enrolment when they persuade other actors to act in accordance with their own intentions. The author of the scallops study, in which enrolment was unsuccessful (the trapping device of the towline failed) concludes: 'Interessement achieves enrolment if it is successful. To describe enrolment is thus to describe the group of multilateral negotiations, trials of strength and tricks that accompany the interessements and enable them to succeed' [4, p. 211].

We apply the concepts of problematisation, interessement and enrolment in this study of portal development in healthcare. Since we made our case study between November 2008 and February 2009, consideration of the new technology planned for introduction in 2010 is not applicable in this paper. 


\section{Method}

This is an interpretive single case study [18] based on the theoretical framework of ANT. Our motivation for the choice of this approach was our intention of filling the gap created by the lack of empirically rich process studies in E-government research [33]. Therefore we needed to collect a rich body of qualitative empirical data.

Interviews were our first research strategy. We began with a search for actors who were associated with the creation of a network for portal development in healthcare. In order to identify the larger network of such actors, in March 2007 we interviewed the manager of a Swedish public development organization-Sjukvårdsrådgivningen SVR AB (Health Advice Online Ltd.). Thereafter we interviewed actors whom other actors had identified as important for our research. We conducted 18 face-to-face, semi-structured interviews (60-90 minutes each). Eight of these interviews were with representatives of Health Advice Online Ltd. that managed the portal development. We also conducted interviews with officials at the Swedish Association of Local Authorities and Regions (SALAR) who represent the county councils, the SALAR commissioning agency entitled the National Centre for Coordinating e-Health, six representatives from two of the largest county councils (Stockholm and Västra Götaland) and a Carelink representative. Carelink is the second public development organization involved in the portal development. These interviews dealt with the activities, actors, intentions and technologies that were relevant to the development of a national healthcare portal.

We also conducted a second set of interviews. From November 2008 to February 2009 we held semi-structured telephone interviews (30-60 minutes each) with 20 of the 21 county council project leaders who had been recently appointed (January 2007 to December 2008). For technical reasons, we were unable to interview the $21^{\text {st }}$ county council project leader. These leaders had the task of coordinating the regional activities required for the connection to the national healthcare portal. In our opinion, owing to their positions and their broad healthcare and technology experience, these leaders were well situated to present valid commentary on the development process. In these interviews we focused on the interessement phase and the activities related to the enrolment of the county councils. We asked about the current and future technological functionality of the new portal, local activities, and meetings in the development process and about interviewees' views of the process. We were especially interested in hearing the project leaders' comments on the pros and cons of the new portal and the critical success factors by which they evaluated it.

According to plans, the launch of the portal was scheduled for the autumn of 2010. As our study was made prior to the launch, there were no healthcare users to interview on their reaction to the portal.

Our second research strategy was the examination of relevant documents that dealt with the gradually evolving ideas about the purpose and use of the portal. We had access to public policy process reports on healthcare and IT, policy documents describing the functional requirements of the proposed portal, as well as strategy documents and evaluations produced by SALAR.

Our third research strategy dealt with the study of the relevant technology. We examined the technologies ("devices") that the actors described as featuring in the portal development. We used documents and interviews as data sources for examining 
these technologies. We also analysed this data in order to create a theoretically informed overview of the problematisation phase that focuses on identification of the problem and its solution (see Section 5.1) and of the interessement phase that focuses on activities and opinions that preceded the enrolment of the county councils (see Section 5.2). Our main goal was to summarize and interpret the county councils' reasons for their enrolment in the development of the healthcare portal (see Section 6).

\section{Case Description}

\subsection{The Problematisation Phase}

To understand the problematisation phase, it is important to understand that most healthcare in Sweden is publicly financed. National authorities regulate Swedish healthcare by setting principles and guidelines although the 21 local county councils are responsible for managing and providing the actual care. Independent political bodies govern these councils that have the right of taxation. In this section we explain the problematisation phase of the national healthcare portal development. This is the phase when prominent actors assume their roles, a problem is identified and a solution is proposed.

In the 1990s some activities in Sweden at the national government level concerned IT infrastructure in healthcare [21], but no legislation was passed related to the issue. The interest among the county councils in the issue varied greatly. In 1998 a national public healthcare portal (Infomedica.se) with information about illnesses, treatments and patient rights was launched by one regional agency and two national agenciesSALAR and Apoteket (the Swedish national pharmaceuticals retailer). Following that launch, various prominent national actors created a national IT strategy for healthcare that was introduced to the public in March 2006. One of its aims was the development of a national healthcare portal for the provision of information and services to healthcare users [22].

SALAR's new national commissioning agency for healthcare managed the followup activities. The development organization, Health Advice Online Ltd., announced that the portal must provide the following [15]: (1) Textual information about 'children', 'pregnancy', 'sex' and 'illnesses', with both national and regional texts, including choices and a waiting-time guarantee; treatments, available at the national and regional levels; drugs available at the national and regional levels; and user rights concerning the waiting-time guarantee, choices and patient committees; (2) Facilities that offer online health tests and self-help therapy; (3) An advanced facility for searching for regional healthcare providers; (4) A national facility for comparing waiting times for county councils' healthcare centres with direct connections for information about illnesses/treatments and waiting times; (5) A forum for asking questions; (6) Individual interactive e-services for making/changing appointments, renewing prescriptions, requesting copies of electronic patient records, contacting healthcare personnel, and requesting tests and test results. All these functions had to be protected by passwords. 
In June 2007 the SALAR commissioning agency assigned Health Advice Online Ltd. the task of developing a national healthcare portal in a "version 0.5 " and a complete 1.0 version [7]. The formulation "version 0.5 " referred to a functionality called Mina Vårdkontakter (My Health Contacts) for individual e-services that was introduced previously by the Stockholm County Council. During the spring of 2008 nearly all the 21 county councils employed project leaders to work on the activities necessary for linking their websites to the national portal. In July 2008, after the bidding process for the contract concluded, an external company was selected to perform the technical development work for the new portal.

\subsection{The Interessement Phase}

At this point, the interessement phase of portal development could begin. During this phase national actors worked directly with the development project. Previously, in 2007, external consultants had reviewed the project organization and content based on a request from the SALAR commissioning agency [27]. These consultants concluded that the project organization should be tightened and its scope should be more clearly defined. The importance of the county councils for the success of the portal was also emphasized. In 2008 the SALAR commissioning agency ordered an analysis. The purpose of this analysis was to calculate the monetary value of the portal to both the healthcare users and the healthcare providers. This information was provided to SALAR and the county councils [17]. Meetings were held in 2008 between the county council project leaders and Health Advice Online Ltd.

Next we describe the county councils' actions and their success criteria in the development of the portal.

Participation in meetings. In 2008 all project leaders in the county councils, with the exception of one newcomer, met with Health Advice Online Ltd. Most leaders commented that the exchanges on the county councils' experiences were the most useful aspects of these meetings. These exchanges were especially valuable to those leaders who had less experience and fewer resources than others. The meetings also dealt with the communication of information about organizational issues related to the national portal. Many interviewees complained about the emphasis on such issues that were such a large item on the meetings' agendas. They also complained about the turbulence created by the problems associated with the project organization per se. Project Leader No. 8 remarked: "It has been a turbulent organization of project work from the side of the Health Advice Online Ltd., and the project leaders have been changed several times. Even though I work in the county council I have never seen such a degree of constant reorganization."

Development of new information. Beginning in the spring of 2007 there were meetings between Health Advice Online Ltd. and the people working with information issues at the county councils. In addition to the national information about patient rights as well as illnesses and treatments (Requirement specification No. 1, listed in Section 5.1), the county councils were allowed to add their own information in accordance with a set of special rules. Many of the county councils had begun work with these texts in 2008 or had plans to do so in 2009. Although one-third of the county councils had similar plans, they were uncertain if this work would be 
finished in 2009 or 2010. The Stockholm County Council had no such plans although it already offered a large body of patient-centred information.

Development of a database of healthcare providers. Two parts of the portal functionality depended on the existence of a database with information about the healthcare providers (Requirement specification No. 3, listed in Section 5.1) and about those providers who offered user e-services in the form of My Health Contacts (Requirement specification No. 6, listed in Section 5.1). The county councils had worked for several years to complete this database. Most county councils reported that they had already completed the database or would do so in 2009. However, the plans for this work by four county councils were rather vague. The Stockholm County Council reported that their database structure was more advanced than the required structure.

Introduction of My Health Contacts. My Health Contacts is a functionality for personal e-services originally created by the Stockholm County Council. In the spring of 2007 the SALAR commissioning agency identified this functionality as part of the portal project that would provide a common facility for all county councils. Most of the county councils said that they had already introduced this functionality, or would do so in 2009. Several county councils were still considering adopting the functionality but had not yet decided what action to take. A few county councils hesitated because they already had a functionality providing personal e-services that was nearly the equivalent of My Health Contacts.

Introduction of a Chlamydia testing facility. As part of the national portal project, an additional functionality was added in 2007-2008. This functionality allowed users to order Chlamydia tests online and to see the results of their tests online. The addition of this new functionality was consistent with the trend in Swedish healthcare to increase the number of medical tests offered. One-third of the county councils' project leaders said they planned to adopt this functionality. Another one-third of the project leaders said no decision had yet been made on the introduction of the functionality. In addition, a few project leaders reported that they already used a different functionality for offering such tests.

Critical success factors for enrolment. According to one third of the interviewees, the success of the portal depends on the quality of information that the regional healthcare providers enter into the system. The perceived usefulness of the functionalities was seen as equally important. Project Leader No. 3 stated: "You have to work to show that this [the portal] is actually useful for the patients and healthcare in a very tangible manner." Another project leader identified My Health Contacts and the ability to search for healthcare providers as success factors. A few interviewees mentioned that economic and organizational aspects of the national project were important for the success in their own regional activities (see Section "Participation in meetings" above).

\section{Discussion}

Our account of the portal development reveals that a large network of actors enrolled in the idea of creating a national healthcare portal. This network included actors on 
both the national and local levels. The most important national actors were the SALAR commissioning agency, the Ministry of Health and Social Affairs, Health Advice Online Ltd. and the external company charged with the developmental work. Together, these actors constituted a global (in our case, national) actor network for creating the space and assembling the resources needed for the innovative work required [14]. This network of national actors, with their portal plan, created an obligatory passage point that the local strategic actors, who would do the actual work of introducing the portal, had to pass through.

In Swedish healthcare, the county councils are part of the local network 'necessary to the successful production of any working device' [20, p. 22]. The explanation lies in the fact that projects in the Swedish public sector are often outside the direct control of the national actors. It has been observed that global actors may have "power over" local actors but may lack the "power to" coerce or influence these local actors [14]. Section 5.2 of this paper describes how the Swedish national actors encouraged the local actors to enrol in the idea of the portal. For example, meetings related to the portal were held with regional representatives, but the county councils maintained their independence as far as the adoption of the proposed IT strategy. Thus the general conclusion about the limitations on the power of global actor networks [14] is relevant in our case study.

Based on a closer analysis of the county councils' activities and the interviewees' views (see Section 5.2) it is possible to reach other general conclusions. Although the development of an E-government system may take several years, our case shows that local actors, such as these county councils, can be persuaded to enrol in and support such projects in their initial phases. Many county councils did initiate regional work with a basic healthcare portal functionality, which was scheduled for completion in 2009, and did participate in meetings at the national level. This observation is important since county councils often act independently on economic, organizational and technological issues. Yet, as the result of various persuasive activities initiated at the national level, some county councils became active supporters of the portal, not only in principle but also in practice.

Our case also shows that both national actors and the local actors viewed the basic technological functionality as strategically important, not only for the portal development, but also for the larger process of generally improving healthcare services. The e-services of My Health Contacts and Chlamydia testing that some county councils adopted exemplified the benefits of the new functionality.

We conclude that it is important to prepare semi-independent local actors technically for enrolment in an IT portal such as the healthcare portal of this study. This preparation means acquainting them with the larger development process as well as with the current and potential technological usefulness of the portal. Using the vocabulary of ANT, the portal functionality presented specific technological enrolment devices that influenced local actors (in our case, the county councils) to commit to the goals of other actors (in our case, SALAR and the Ministry of Health and Social Affairs, among others),

Furthermore, the issue of usefulness has a dimension related to the future potential of the healthcare portal. The portal version 1.0 consists of an infrastructure with a simple but useful functionality that has some interaction with local healthcare systems. The real value of the portal may very well be that it supports activities such 
as direct appointment scheduling and patient access to electronic health records. Therefore, to safeguard the new portal as a platform for future development ("version 2.0 "), it is necessary that the organizational aspects of continued joint development be pursued, or administered, at the national level.

In sum, a simple functionality that offers perceived and expected usefulness is an important device for the enrolment of actors in E-government contexts. In IS research the concept of (perceived) usefulness [28] is often used in ex post facto evaluations that justify technology use [24]. In the context of E-government in general, and in healthcare exemplified by portal development in particular, the concept of usefulness has a specific strategic flavour. The concept of usefulness can be a multifaceted motivator, if not the motivator, for the enrolment of local actors. This is so, even if one must pose the following question: usefulness - for whom and for what purpose?

In any discussion of the concept of usefulness it is important to consider the multiple logics represented as well as the important persuasive activities in the interessement phase that have the potential to convince local strategic actors ("power to") in the absence of global actors' influence/control ("power over") [14]. The perceived and expected usefulness is, of course, closely related to the notion of existing, emerging and future users and the use possibilities. Thus documents that outline technology strategies do not feature usefulness strategies [32]. Instead, they feature important narrative enrolment devices in basic technology development processes. In our case, the national actors suggested that the related issue of benefit management must increasingly be taken into account before, during and after the portal development [9]. Our conclusion is therefore that usefulness in its various forms seems to be both political and politically important in E-government contexts. Future research should examine the nuances in meanings of usefulness, and the significance of this concept for enrolment.

The intent of our ANT-based analysis of the politics of network formation in an Egovernment context, with its focus on local actors and their enrolment in a technological functionality, is to achieve quality of results and to avoid reporting extensive empirical detail. This intention is a response to the criticism of ANT that charges that ANT described rather than explains [30]. Our study, although it uses ANT as a theoretical framework, tries to explain rather than to present a long and detailed description of network formation in an E-government context. Therefore we performed an empirically based analysis at a general as well as a specific level in order to fairly represent the actions and opinions of the actors. We have illustrated the potential of various approaches when treating the different stages in the process of translation as well as a certain group of actors [4]. In examining certain phases closely, such as the interessement phase, there is also a problem concerning the stylistic aspects of descriptions. In many qualitative E-government process studies [33], the majority of examples have more a textbook character than the research articles do $[3,10]$.

\section{Conclusion}

This paper contributes to E-government studies with particular reference to those studies that use ANT. In its focus on the strategic aspects of one specific group of actors in network formation the paper also contributes to ANT more generally by 
testing a particular approach in data capture and analysis. We suggest the following implications of this research. 1) Basic functionalities that seem simple may have strategic importance for enrolling semi- independent actors in portal development. These functionalities act as enrolment devices because of their ability to communicate the usefulness of a function. 2) Due to the complexity of the environment and the extent of the development process, stable project organization in the long-term that safeguards future work is necessary. 3) Enrolment is a top-down process in which global (i.e. national in our case) actors try to lead local actors. However, the local actors exhibit a certain independence that results in a self-organizing attitude. An implication for practice is therefore the symbolic as well as concrete value of technology to show usefulness in elongated development processes.

We recognize that a limitation of our research is that it was conducted during the actual development of the portal instead of ex post facto. Therefore our paper does not offer a final evaluation of the portal since our research was conducted during the "work in progress." Nevertheless, this timing of the research was in some respects a strength since we were able to capture opinions about current events instead of ex post facto rationalizations. A second limitation is that our results are derived from a single case, necessarily calling into question the generalizability of our findings. However, because our study is based on a relatively large sample-interview data from 20 county councils-it has validity as a comparative case study.

Acknowledgement. Thanks are due to the Bank of Sweden Tercentenary Foundation for funding this research.

\section{References}

1. Aykac, S.S., et al.: An Actor-Network Theory (ANT) approach to Turkish E-government gateway initiative. In: 1st International Conference on eGovernment \& eGovernance (ICEGEG 2009), Ankara, Turkey (2009)

2. Ayyad, M.: Using the Actor Network Theory to interpret e-Government implementation barriers. In: ICEGOV 2009, Bogota, Colombia, November 10-13 (2009)

3. Bellamy, C., Taylor, C.: Governing in the Information Age. University Press, Buckingham (1998)

4. Callon, M.: Some Elements of a Sociology of Translation: Domestication of the Scallops and the Fishermen of St Brieuc Bay. In: Law, J. (ed.) Power, Action, and Belief, pp. 196233. Routledge \& Keegan Paul, London (1986)

5. Callon, M., Muniesa, F.: Economic Markets as Calculative Collective Devices. Organization Studies 26(8), 1229-1250 (2005)

6. Cho, S., Mathiassen, L., Nilsson, A.: ontextual Dynamics During Health Information Systems Implementation: An event-based actor-network approach. European Journal of Information Systems 17, 614-630 (2008)

7. Commissioning agency of SALAR: Assignment to the Development Organization. Health Advice Online Ltd [Sjukvårdsrådgivningen AB. Upphandlingsunderlag. Vården på webben]. Health Advice Online Ltd, Stockholm (2007)

8. Czarniawska, B., Hernes, T.: Actor-Network Theory and Organizing. Lund and Copennhagen, Liber and Copenhagen Business School (2005) 
9. E-delegation: Guidance for Benefit Management [Vägledning för nyttorealisering]. Report. Stockholm, E-delegationen (2011)

10. Fountain, J.: Building the Virtual State: Information Technology and Institutional Change. Brookings Institution Press, Washington (2001)

11. Glenton, C., Paulsen, E.: Oxman, A. Portals to Wonderland: Health Portals Lead to Confusing Information about the Effects of Health Care, Medical Informatics and Decision Making 5(7) (2005)

12. Guah, M., et al.: Augmenting Successful UK healthcare IS Adoption and Diffusion: an Analysis of Inherent and Emergent Organizational Structures. In: 22nd Bled eConference eEnablement, Bled, Slovenia, June 14-17 (2009)

13. Hanseth, O., Jacucci, E., Grisot, M., Aanestad, M.: Reflexive Standardisation: Side Effects and Complexity in Standard Making. MIS Quarterly 30, 563-581 (2006)

14. Heeks, R., Stanforth, C.: Understanding e-government Project Trajectories from an ActorNetwork Perspective. European Journal of Information Systems 16, 165-177 (2007)

15. Health Advice Online Ltd: Requirement Specification. Product Overview [Kravspecifikation. Produktöversikt]. Stockholm (2008)

16. Holmström, J., Robey, D.: Inscribing Organizational Change with Information Technology. In: Czarniawska, B., Hernes, T. (eds.) Actor-network Theory and Organizing, pp. 165-187. Liber and Copenhagen Business School, Lund and Copenhagen (2005)

17. Jerligård, E.: PENG-analysis [PENG-analys. Vården på webben januari-mars 2009]. Stockholm, SALAR (2009)

18. Klein, H., Myers, M.: A Set of Principles for Conducting and Evaluating Interpretive Field Studies in Information Systems. MIS Quarterly 23(1), 67-94 (1999)

19. Latour, B.: Science in Action. How to Follow Scientists and Engineers through Society. Harvard University Press, Cambridge (1987)

20. Law, J., Callon, M.: The life and Death of an Aircraft: A Network Analysis of Technical Change. In: Bijker, W., Law, J. (eds.) Shaping Technology/Building Society: Studies in Socio-technical Change, pp. 21-52. MIT Press, Cambridge (1992)

21. Ministry of Health and Social Affairs. Working Report from the Study of the Information Structure in Healthcare. Laws, Classification and Information Technology. [Arbetsrapporter från Utredningen om informationsstrukturen i hälso- och sjukvården. 2. Gemensamma regler: lagstiftning, klassifikationer och informationsteknologi]. Ministry of Health and Social Affairs, Stockholm (1991)

22. Ministry of Health and Social Affairs et al : National IT Strategy in Healthcare [Nationell IT-strategi för vård och omsorg]. Ministry of Health and Social Affairs. Stockholm (2006)

23. Muganda Ochara, N.: Assessing Irreversibility of an E-Government project in Kenya: Implications for Governance. Government Information Quarterly 27, 89-97 (2009)

24. Premkumar, G., Bhattacherjee, A.: Explaining Information Technology Usage: A Test of Competing Models, Omega. International Journal of Management Science 36, 64-75 (2008)

25. Ranerup, A.: Electronic Government as a Combination of Human and Technological Agency: Testing the Principle of Symmetry. Information Polity 12(3), 153-168 (2007)

26. Ranerup, A.: Decision Support Systems for Public Policy Implementation: The Case of Pension Reform. Social Science Computer Review, 428-445 (2008)

27. SALAR: Following up Report 2 of the Project Healthcare on the Web [Uppföljning 2 av project Vård på webben. June 18, 2008] Stockholm, Commissioning agency of SALAR \& Öhrlings/PriceWaterhouseCooper (2008)

28. Seddon, P.: A Respecification and Extention of the DeLone and McLean model of IS Success. Information Systems Research 8(3), 240-253 (1997) 
29. Skiftenes-Flak, L., Nordheim, S., Munkvold, B.: Analyzing Stakeholder Diversity in G2G Efforts: Combining Descriptive Stakeholder Theory and Dialectic Process Theory. eService Journal 6(2), 3-23 (2007)

30. Walsham, G.: Actor-Network Theory and IS research: Current Status and Future Prospects. In: Proceedings of the IFIP TC8 WG 8.2 International Conference on Information Systems and Qualitative Research, pp. 466-480. Chapman and Hall, London (1997)

31. Whitley, E., Rukanova, B.: A Symmetrical Analysis of the Border Control Information System for People and Trade. In: ECIS 2008. University of Regensburg, Germany (2008)

32. Wilkie, A., Michael, M.: Expectations and Mobilisation: Enacting Future Users. Science, Technology \& Human Values 34, 504-522 (2009)

33. Yildiz, M.: E-government Research: Reviewing the Literature, Limitations, and Ways Forward. Government Information Quarterly 24, 646-665 (2007) 